\title{
Effects of green tea on weight maintenance after body-weight loss
}

\author{
Eva M. R. Kovacs, Manuela P. G. M. Lejeune, Ilse Nijs and Margriet S. Westerterp-Plantenga* \\ Department of Human Biology, Maastricht University, Maastricht, The Netherlands
}

(Received 14 February 2003 - Revised 22 September 2003 - Accepted 7 November 2003)

\begin{abstract}
The present study was conducted to investigate whether green tea may improve weight maintenance by preventing or limiting weight regain after weight loss of 5 to $10 \%$ in overweight and moderately obese subjects. The study had a randomised, parallel, placebo-controlled design. A total of 104 overweight and moderately obese male and female subjects (age $18-60$ years; BMI $25-35 \mathrm{~kg} / \mathrm{m}^{2}$ ) participated. The study consisted of a very-low-energy diet intervention (VLED; $2 \cdot 1 \mathrm{MJ} / \mathrm{d}$ ) of 4 weeks followed by a weight-maintenance period of 13 weeks in which the subjects received green tea or placebo. The green tea contained caffeine $(104 \mathrm{mg} / \mathrm{d}) \mathrm{and}$ catechins $(573 \mathrm{mg} / \mathrm{d}$, of which $323 \mathrm{mg}$ was epigallocatechin gallate). Subjects lost 6.4 (SD 1.9) $\mathrm{kg}$ or 7.5 (SD 2.2) \% of their original body weight during the VLED $(P<0.001)$. Body-weight regain was not significantly different between the green tea and the placebo group (30.5 (SD 61.8$) \%$ and $19 \cdot 7$ (SD 56.9) \%, respectively). In the green tea treatment, habitual high caffeine consumption was associated with a higher weight regain compared with habitual low caffeine consumption (39 (SD 17) and 16 (SD 11) \%, respectively; $P<0 \cdot 05$ ). We conclude that weight maintenance after $7.5 \%$ body-weight loss was not affected by green tea treatment and that habitual caffeine consumption affected weight maintenance in the green tea treatment.
\end{abstract}

Caffeine: Epigallocatechin gallate: Energy expenditure: Substrate oxidation: Obesity

The increasing incidence of obesity is a recognised medical problem in developed countries (Seidell, 1995). Obesity is associated with an increased risk of developing serious disorders, including hypertension, dyslipidaemia, cardiovascular disease, non-insulin-dependent diabetes mellitus, gallbladder disease, respiratory dysfunction, gout and osteoarthritis (Pi-Sunyer, 1993). Factors suggested to be related to the development of obesity are increased energy intake, especially from increased energy density through increased fat intake (Westerterp-Plantenga, 2001), and decreased energy expenditure, particularly from reduced physical activity (Westerterp, 2001). Bodyweight and fat loss can thus be achieved by reducing energy intake and/or by increasing energy expenditure. The treatment of obesity is beneficial. Modest weight loss, i.e. 5 to $10 \%$ of the initial body weight, which is a realistic goal for most individuals, is associated with a marked health improvement (Goldstein, 1992; van Gaal et al. 1997). However long-term maintenance of the body weight lost can be described as unsuccessful. Most studies on weight maintenance show that weight regain is usually the case (Wadden et al. 1988; Kramer et al. 1989; Pasman et al. 1997a,b, 1999), indicating that subjects are not able to change their eating and activity behaviour adequately (Westerterp-Plantenga et al. 1998). Intervention strategies for promoting long-term weight maintenance are therefore needed in order to treat obesity effectively. The limited long-term effectiveness of conventional weight management (dietary intervention, physical activity and behavioural therapy) leads to the development of alternative weight-reduction strategies. A rapidly growing therapeutic area, largely embraced by the general public, is the use of natural ingredients.

One of these ingredients is green tea. Green tea, rich in catechin polyphenols, especially epigallocatechin gallate, and caffeine, has been shown to increase $24 \mathrm{~h}$ energy expenditure and fat oxidation (Dulloo et al. 1999). Therefore, we hypothesised that green tea would have a limiting effect on body-weight regain after weight loss, probably through a thermogenic effect. The aim of the present study was to investigate whether green tea may improve weight maintenance by preventing or limiting weight regain after weight loss of 5 to $10 \%$ in overweight and moderately obese subjects.

\section{Method \\ Subjects \\ A total of 140 male and female subjects, aged between 18 and 60 years, were recruited for the present study. They underwent a medical screening. Selection resulted in 120 subjects who were in good health, non-smokers, not using medication and at most were moderate alcohol}


users (<two glasses/d), with a BMI between 25 and $35 \mathrm{~kg}$ / $\mathrm{m}^{2}$. They all gave their written informed consent. The medical ethics committee of the Academic Hospital in Maastricht approved the study. Subjects were randomised to an intensive ( $n$ 80) or an extensive group ( $n$ 40). The intensive group underwent all the measurements. The extensive group underwent the same measurements as the intensive group, except for resting energy expenditure (REE), substrate oxidation and physical activity. During the first 4 weeks, sixteen subjects dropped out, due to various reasons: moving house, changing jobs, or not being able to cope with the first diet, or to continue the schedule with visits to the University. Finally, 104 subjects completed the study, i.e. seventy in the intensive group and thirty-four in the extensive group.

\section{Experimental design: baseline measurements}

Body weight and body mass index. Body weight was measured on a digital balance (model 707, weighing accuracy of $0.1 \mathrm{~kg}$; Seca, Hamburg, Germany) with subjects in underwear, in the fasted state and after voiding their bladder. Height was measured using a wall-mounted stadiometer (model 220; Seca, Hamburg, Germany). BMI was calculated as body weight/height ${ }^{2}\left(\mathrm{~kg} / \mathrm{m}^{2}\right)$.

Body composition. The distribution of fat was investigated by measuring the waist and hip circumferences and by the calculation of the waist:hip ratio. The waist circumference was measured at the site of the smallest circumference between the rib cage and the ileac crest, with the subjects in a standing position. The hip circumference was measured at the site of the largest circumference between the waist and the thighs. The waist:hip ratio was calculated by dividing the waist circumference by the hip circumference.

Total body water was measured using the ${ }^{2} \mathrm{H}$ dilution technique (Schoeller et al. 1980; van Marken Lichtenbelt et al. 1994). In the evening, the subjects ingested a dose of ${ }^{2} \mathrm{H}$-enriched water after collecting a background urine sample. After consumption of the ${ }^{2} \mathrm{H}$-enriched water no more fluid or food was consumed. The following morning a urine sample from the second voiding was collected between 08.00 and 10.00 hours. ${ }^{2} \mathrm{H}$ concentration in the urine samples was measured using an isotope ratio mass spectrometer (Micromass Optima, Manchester, UK). Total body water was obtained by dividing the measured ${ }^{2} \mathrm{H}$ dilution space by 1.04 (Schoeller et al. 1980). Fatfree mass (FFM) was calculated by dividing the total body water by the hydration factor of $0 \cdot 73$. By subtracting FFM from body weight, fat mass was obtained. Fat mass expressed as a percentage of body weight is body fat percentage.

Attitude towards eating. To determine whether attitude towards food intake changed during the experiment, a Dutch translation of the three-factor eating questionnaire was used (Stunkard \& Messick, 1985; Westerterp-Plantenga et al. 1999). In addition, the Herman-Polivy questionnaire (Herman \& Polivy, 1980) was used to determine the frequency of dieting.

Caffeine intake. Habitual caffeine intake was determined during an interview using a questionnaire specific for caffeine-containing products. Subjects were asked about the type and the amount of caffeine-containing products that they normally consumed during 1 week.

Post-absorptive appetite profile. To determine the post-absorptive appetite profile, hunger and satiety were rated on anchored $100 \mathrm{~mm}$ visual analogue scales in the morning before breakfast.

Blood parameters. A fasted blood sample of $10 \mathrm{ml}$ was taken and mixed with EDTA to prevent clotting. Plasma was obtained by centrifugation $\left(4^{\circ} \mathrm{C}, 3000 \mathrm{rpm}, 10 \mathrm{~min}\right)$, frozen in liquid $\mathrm{N}_{2}$ and stored at $-80^{\circ} \mathrm{C}$ until further analysis. Plasma glucose concentrations were determined using the hexokinase method (Glucose HK 125 kit; ABX Diagnostics, Montpellier, France). The Wako NEFA C-kit (Wako Chemicals, Neuss, Germany) was used to determine non-esterified fatty acid concentrations. Insulin concentrations were measured using a radioimmunoassay kit (Insulin RIA-100; Pharmacia, Uppsala, Sweden). The glycerolkinase method was used to determine glycerol concentrations (Boehringer Mannheim GmbH, Mannheim, Germany). Triacylglycerols were measured using the GPO-trinder kit (Sigma Diagnostics Inc., St Louis, MO, USA). The $\beta$-hydroxybutyrate dehydrogenase method (Sigma Diagnostics Inc., St Louis, MO, USA) was used to determine $\beta$-hydroxybutyrate concentrations. Leptin concentrations were measured using a human leptin radioimmunoassay kit (Linco Research Inc., St Charles, MO, USA).

Adverse events. Adverse events during treatment were recorded using a specific questionnaire.

Resting energy expenditure and substrate oxidation. REE and substrate oxidation were measured by means of an open circuit ventilated hood system. REE was measured in the morning with subjects in a fasted state while lying supine for $30 \mathrm{~min}$. Gas analysis was performed by a paramagnetic $\mathrm{O}_{2}$ analyser and an $\mathrm{IR} \mathrm{CO}_{2}$ Servomex type 500A (Crowborough, Sussex, UK), similar to the analysis system described by Schoffelen et al. (1997). Calculation of REE was based upon Weir's formulas (Weir, 1949). Respiratory quotient was calculated as $\mathrm{CO}_{2}$ produced/ $\mathrm{O}_{2}$ consumed.

Physical activity. Physical activity level (PAL) and total energy expenditure (TEE) were determined using a Computer Science and Applications Inc. uni-axial accelerometer (Ekelund et al. 2000) or a tri-axial accelerometer for movement registration (Tracmor) (Goris et al. 2001) during 1 week. Subjects were wearing the uni-axial accelerometer or Tracmor during waking hours in a belt at the back of the waist.

PAL was calculated (Ekelund et al. 2000) using data from the uni-axial accelerometer:

$$
\mathrm{PAL}=(0 \cdot 000001379 \times(\text { counts } / \mathrm{d} \times 5))+1 \cdot 113 .
$$

PAL and TEE were calculated (Goris et al. 2001) using data from the Tracmor:

$$
\begin{gathered}
\mathrm{TEE}=-1.259+(1.552 \times \mathrm{REE})+(0.076 \times \text { counts } / \mathrm{min}) \\
\mathrm{PAL}=\mathrm{TEE} / \mathrm{REE} .
\end{gathered}
$$

\section{Experimental design: body-weight loss period}

A very-low-energy diet $(2 \cdot 1 \mathrm{MJ} / \mathrm{d})$ intervention was offered during 4 weeks, in order to let all subjects lose weight. 
The very-low-energy diet (Modifast ${ }^{\circledR}$; Novartis Nutrition, Breda, The Netherlands) was supplied in three sachets daily, dissolved in water to obtain a milk shake, pudding, soup or muesli. Vegetables and fruit were allowed in addition to Modifast ${ }^{\circledR}$. The aim was a body-weight loss of at least $4 \mathrm{~kg}$.

After this body-weight-loss period, the measurements described earlier (p. 434) for baseline measurements were repeated (Table 1).

\section{Experimental design: weight-maintenance period}

For assessment during the weight-maintenance period of 13 weeks, the subjects, stratified for sex, BMI, age, cognitive restraint (factor 1, three-factor eating questionnaire) and REE, were divided into two groups. The subjects received $450 \mathrm{mg}$ green tea or placebo (six capsules/d, i.e. two capsules with breakfast, lunch, and dinner). The composition of the green tea capsule was analysed by HPLC and is given in Table 2. Consequently, the ingestion of capsules containing green tea provided daily a total of $104 \mathrm{mg}$ caffeine and $573 \mathrm{mg}$ catechins, of which $323 \mathrm{mg}$ was epigallocatechin gallate. The administration of the supplementation was double blind. The green tea capsules and the placebo capsules were indistinguishable. Finally, fifty-one (thirty-six female, fifteen male) subjects participated in the 'green tea' group and fifty-three (forty-two female, eleven male) subjects participated in the placebo group. With respect to the intensive group, thirty-three subjects belonged to the 'green tea' group and thirty-seven subjects to the placebo group.

After this weight-maintenance period, the measurements described earlier (p. 434) for baseline measurements were repeated (Table 1). In addition, body weight was determined 4 and 7 weeks after the start of the weightmaintenance period.

\section{Data analysis}

Data are presented as means and standard deviation. A two-factor repeated-measures ANOVA was carried out to determine possible differences between the green tea and placebo group in all measured parameters over time. When appropriate a factorial ANOVA was used for analysing differences between the treatment groups. Post hoc analyses were done with the Scheffé $F$ test. A difference with $P<0.05$ was regarded as statistically significant. Statistical procedures were performed by using Statview SE + Graphics (Abacus Concepts, Berkeley, CA, USA, 1988).

\section{Results}

For all parameters measured, no different treatment effect was observed between men and women. Therefore the data for men and women were combined. Habitual caffeine consumption did not differ between the green tea and the placebo group.

The habitual caffeine consumption of the green tea group was 369 (SD 227) $\mathrm{mg} / \mathrm{d}$, with a range of $1-991 \mathrm{mg} / \mathrm{d}$ (n 19 with $<300 \mathrm{mg}$ caffeine/d; $n 32$ with $>300 \mathrm{mg}$ caffeine/d).

The habitual caffeine consumption of the placebo group was 358 (SD 190) $\mathrm{mg} / \mathrm{d}$, with a range of $39-996 \mathrm{mg} / \mathrm{d}(n 19$ with $<300 \mathrm{mg}$ caffeine/d; $n 32$ with $>300 \mathrm{mg}$ caffeine/d).

\section{Body-weight-loss period}

During the body-weight-loss period, the subjects lost $6 \cdot 4$ (SD 1.9) $\mathrm{kg}$ or 7.5 (SD 2.2) \% of their original body weight $(P<0 \cdot 01)$. This loss consisted of $4.0(\mathrm{SD} 6 \cdot 2) \mathrm{kg}$ fat mass and of 2.4 (SD 2.2) $\mathrm{kg}$ FFM. Waist circumference decreased during body-weight loss. Attitudes towards

Table 1. Subject characteristics of the green tea ( $n 51$; thirty-six female, fifteen male) and the placebo ( $n$ 53; forty-two female, eleven male) group at baseline, after 4 weeks body-weight loss and after 13 weeks weight maintenance

(Mean values and standard deviations)

\begin{tabular}{|c|c|c|c|c|c|c|c|c|c|c|c|c|}
\hline & \multicolumn{4}{|c|}{ Baseline } & \multicolumn{4}{|c|}{ After 4 weeks body-weight loss } & \multicolumn{4}{|c|}{ After 13 weeks weight maintenance } \\
\hline & \multicolumn{2}{|c|}{ Green tea } & \multicolumn{2}{|c|}{ Placebo } & \multicolumn{2}{|c|}{ Green tea } & \multicolumn{2}{|c|}{ Placebo } & \multicolumn{2}{|c|}{ Green tea } & \multicolumn{2}{|c|}{ Placebo } \\
\hline Body mass (kg) & $85 \cdot 1$ & $11 \cdot 5$ & 85.4 & $10 \cdot 3$ & $79 \cdot 3^{*}$ & $10 \cdot 8$ & $78 \cdot 4^{*}$ & $9 \cdot 3$ & $81 \cdot 0^{*}$ & $12 \cdot 6$ & $79 \cdot 5^{\star}$ & $10 \cdot 7$ \\
\hline BMI $\left(\mathrm{kg} / \mathrm{m}^{2}\right)$ & $29 \cdot 7$ & 2.9 & $29 \cdot 7$ & $2 \cdot 3$ & $27 \cdot 7^{*}$ & $2 \cdot 7$ & $27 \cdot 3^{*}$ & $2 \cdot 3$ & $28 \cdot 2^{*}$ & $3 \cdot 2$ & $27 \cdot 6^{*}$ & 2.9 \\
\hline Waist (mm) & 943 & 88 & 946 & 81 & $895^{\star}$ & 81 & $876^{\star}$ & 70 & $897^{\star}$ & 105 & $875^{\star}$ & 83 \\
\hline Fat-free mass $(\mathrm{kg})$ & 53.5 & $9 \cdot 2$ & 53.3 & $9 \cdot 3$ & $50 \cdot 9^{\star}$ & $9 \cdot 1$ & $50 \cdot 8^{*}$ & $8 \cdot 5$ & $52 \cdot 6^{*}$ & $9 \cdot 7$ & $52 \cdot 3^{*}$ & $9 \cdot 2$ \\
\hline Fat mass $(\mathrm{kg})$ & $31 \cdot 6$ & $7 \cdot 1$ & $32 \cdot 0$ & $5 \cdot 3$ & $28 \cdot 5^{\star}$ & $7 \cdot 1$ & $27 \cdot 2^{*}$ & $5 \cdot 3$ & $28 \cdot 7^{*}$ & $7 \cdot 4$ & $26 \cdot 9^{*}$ & $6 \cdot 5$ \\
\hline Percentage body fat & $37 \cdot 2$ & $6 \cdot 4$ & $37 \cdot 7$ & $5 \cdot 4$ & $35 \cdot 9^{\star}$ & $7 \cdot 0$ & $35 \cdot 1^{*}$ & $6 \cdot 1$ & $35 \cdot 2^{*}$ & $6 \cdot 6$ & $33.9^{*}$ & $6 \cdot 1$ \\
\hline F1‡ & $7 \cdot 2$ & $3 \cdot 6$ & $7 \cdot 6$ & $4 \cdot 0$ & 9.5 & $4 \cdot 7$ & $9 \cdot 7$ & $4 \cdot 5$ & $8 \cdot 9$ & $4 \cdot 2$ & $10 \cdot 6^{\star}$ & $4 \cdot 8$ \\
\hline F2‡ & $6 \cdot 1$ & 2.9 & $6 \cdot 3$ & $2 \cdot 4$ & 5.4 & $2 \cdot 5$ & $5 \cdot 3$ & 2.5 & $5 \cdot 3$ & 2.9 & $5 \cdot 2$ & 2.5 \\
\hline F3‡ & $4 \cdot 8$ & 3.4 & $5 \cdot 5$ & $3 \cdot 6$ & 4.4 & 3.5 & $4 \cdot 7$ & $3 \cdot 7$ & $3 \cdot 6$ & $3 \cdot 1$ & $3 \cdot 7$ & 3.4 \\
\hline $\mathrm{HP}$ & $15 \cdot 5$ & $4 \cdot 1$ & $16 \cdot 5$ & 3.5 & $16 \cdot 1$ & $4 \cdot 1$ & $17 \cdot 4$ & 3.4 & $16 \cdot 4$ & 3.7 & $17 \cdot 5$ & 3.4 \\
\hline Hunger (mm VAS) & 34.6 & $27 \cdot 0$ & 38.5 & $27 \cdot 2$ & $34 \cdot 1$ & $24 \cdot 8$ & 35.9 & $24 \cdot 9$ & $29 \cdot 2$ & $17 \cdot 8$ & $34 \cdot 0$ & $21 \cdot 2$ \\
\hline Rate of regain $(g / d)$ & & & & & & & & & $18 \cdot 9$ & $40 \cdot 5$ & $11 \cdot 6$ & $43 \cdot 9$ \\
\hline
\end{tabular}

HP, Herman-Polivy questionnaire score (Herman \& Polivy, 1980); VAS, visual analogue scale (fasting state before breakfast).

* Mean value was significantly different to that at baseline $(P<0.01)$ (repeated-measures ANOVA).

†For details of procedures, see pp. 432-433.

$\ddagger$ Cognitive restraint (F1), disinhibition (F2), hunger (F3) scores from the three-factor eating questionnaire (Stunkard \& Messick, 1985)

$\S$ Body-weight regain expressed as percentage of body-weight loss. 
Table 2. Composition of the green tea and placebo capsules (mg/capsule)

\begin{tabular}{lrr}
\hline & Green tea & Placebo \\
\hline Caffeine & $17 \cdot 25$ & \\
Total catechins & 95.46 & \\
Catechin & 1.01 & \\
Epicatechin & $5 \cdot 76$ & \\
Gallocatechin & $1 \cdot 11$ & \\
Epigallocatechin & 3.77 & \\
Catechin gallate & 0.81 & \\
Epicatechin gallate & 20.74 & \\
Gallocatechin gallate & 8.45 & \\
Epigallocatechin gallate & 53.81 & \\
Placebo & 337.29 & 450.00 \\
Total & 450.00 & 450.00 \\
\hline
\end{tabular}

eating did not change significantly. Also hunger and satiety in the fasted state before breakfast did not change significantly (Table 1). REE decreased during body-weight loss. Also respiratory quotient decreased, indicating increased fat oxidation. No significant changes were observed for PAL and TEE (Table 3). Fasted plasma glucose, insulin, triacylglycerol and leptin decreased, while plasma $\beta$-hydroxybutyrate, non-esterified fatty acids and glycerol increased with body-weight loss (Table 4). No differences were observed between the two groups that followed different treatments during the weight-maintenance period.

\section{Weight-maintenance period}

During the weight-maintenance period, body-weight regain, expressed as a percentage of body-weight loss, and the rate of regain were not significantly different between the treatments (Table 1). Body-weight regain was mainly due to increased FFM, while fat mass almost did not change. Cognitive restraint (factor 1, three-factor eating questionnaire) increased during weight regain in the placebo group $(P<0.01)$, but not in the green tea group. However, cognitive restraint at the end of the weight-maintenance period was not different between the treatments. Hunger and satiety in the fasted state before breakfast did not change significantly. REE and respiratory quotient were not significantly different from baseline values at the end of the weight-maintenance

Table 3. Energy expenditure and substrate oxidation of the green tea and the placebo group at baseline, after 4 weeks body-weight loss and after 13 weeks weight maintenance†

(Mean values and standard deviations)

\begin{tabular}{|c|c|c|c|c|c|c|c|c|c|c|c|c|}
\hline & \multicolumn{4}{|c|}{ Baseline } & \multicolumn{4}{|c|}{ After 4 weeks body-weight loss } & \multicolumn{4}{|c|}{ After 13 weeks weight maintenance } \\
\hline & \multicolumn{2}{|c|}{ Green tea } & \multicolumn{2}{|c|}{ Placebo } & \multicolumn{2}{|c|}{ Green tea } & \multicolumn{2}{|c|}{ Placebo } & \multicolumn{2}{|c|}{ Green tea } & \multicolumn{2}{|c|}{ Placebo } \\
\hline & Mean & SD & Mean & SD & Mean & SD & Mean & SD & Mean & SD & Mean & SD \\
\hline REE $(M J / d) \ddagger$ & $6 \cdot 9$ & 1.2 & $7 \cdot 0$ & 0.9 & $6 \cdot 3^{*}$ & 1.0 & $6 \cdot 3^{*}$ & 0.7 & $6 \cdot 8$ & $1 \cdot 2$ & 6.5 & 0.8 \\
\hline$R Q \ddagger$ & 0.84 & 0.05 & 0.83 & 0.05 & $0.80^{\star}$ & 0.06 & $0.78^{*}$ & 0.04 & 0.85 & 0.06 & 0.85 & 0.05 \\
\hline PAL§ & 1.6 & 0.1 & 1.6 & $0 \cdot 1$ & 1.6 & $0 \cdot 1$ & $1 \cdot 6$ & 0.2 & 1.6 & 0.2 & 1.6 & $0 \cdot 1$ \\
\hline TEE $(M J / d) \S$ & 11.1 & $2 \cdot 3$ & $10 \cdot 9$ & 1.5 & $10 \cdot 2$ & $2 \cdot 3$ & $10 \cdot 0$ & 1.3 & $11 \cdot 2$ & $2 \cdot 2$ & $10 \cdot 3$ & 1.5 \\
\hline
\end{tabular}

REE, resting energy expenditure; $R Q$, respiratory quotient; $P A L$, physical activity level; TEE, total energy expenditure.

* Mean value was significantly different to that at baseline $(P<0.01)$ (repeated-measures ANOVA).

†For details of procedures, see pp. 432-433.

$\ddagger$ Thirty-three subjects received green tea (twenty-three female, ten male); thirty-seven received the placebo (twenty-eight female, nine male).

$\S$ Twelve subjects received green tea (seven female, five male); twenty-six received the placebo (twenty female, six male).

Table 4. Fasting plasma parameters of the green tea ( $n 51$; thirty-six female, fifteen male) and the placebo ( $n 53$; forty-two female, eleven male) group at baseline, after 4 weeks body-weight loss and after 13 weeks weight maintenance

(Mean values and standard deviations)

\begin{tabular}{|c|c|c|c|c|c|c|c|c|c|c|c|c|}
\hline & \multicolumn{4}{|c|}{ Baseline } & \multicolumn{4}{|c|}{ After 4 weeks body-weight loss } & \multicolumn{4}{|c|}{ After 13 weeks weight maintenance } \\
\hline & \multicolumn{2}{|c|}{ Green tea } & \multicolumn{2}{|c|}{ Placebo } & \multicolumn{2}{|c|}{ Green tea } & \multicolumn{2}{|c|}{ Placebo } & \multicolumn{2}{|c|}{ Green tea } & \multicolumn{2}{|c|}{ Placebo } \\
\hline Glucose (mmol/l) & $5 \cdot 7$ & 0.9 & $5 \cdot 4$ & 0.4 & $5 \cdot 3^{*}$ & 0.6 & $5 \cdot 1^{\star}$ & 0.3 & 5.4 & 0.8 & $5 \cdot 3$ & 0.4 \\
\hline Insulin (U/I) & $11 \cdot 0$ & $5 \cdot 3$ & $10 \cdot 3$ & 3.6 & $7 \cdot 6^{\star}$ & $3 \cdot 2$ & $6 \cdot 2^{*}$ & $1 \cdot 8$ & $9 \cdot 2$ & $6 \cdot 8$ & $7 \cdot 6$ & $3 \cdot 0$ \\
\hline $\mathrm{BHB}(\mu \mathrm{mol} / \mathrm{l})$ & 250 & 79 & 264 & 104 & $439^{*}$ & 283 & $559^{\star}$ & 327 & 265 & 91 & 251 & 86 \\
\hline NEFA $(\mu \mathrm{mol} / \mathrm{l})$ & 324 & 132 & 323 & 125 & $437^{*}$ & 243 & $401^{*}$ & 165 & 276 & 132 & 299 & 180 \\
\hline $\mathrm{TG}(\mathrm{mmol} / \mathrm{l})$ & 1257 & 666 & 1384 & 629 & $957^{*}$ & 339 & $962^{*}$ & 315 & 1119 & 498 & 1252 & 606 \\
\hline Leptin $(\mu \mathrm{g} / \mathrm{l})$ & $22 \cdot 4$ & 12.9 & $21 \cdot 8$ & $9 \cdot 6$ & $10 \cdot 5^{\star}$ & 7.5 & $8 \cdot 4^{\star}$ & 4.9 & $19 \cdot 2$ & $11 \cdot 0$ & $18 \cdot 1$ & $11 \cdot 6$ \\
\hline
\end{tabular}

BHB, $\beta$-hydroxybutyrate; NEFA, non-esterified fatty acids; TG, triacylglycerol.

* Mean value was significantly different to that at baseline $(P<0.01)$ (repeated-measures ANOVA).

†For details of procedures, see pp. 432-433. 
period (Table 3). Also all fasted plasma parameters almost returned to baseline concentrations after the weight-maintenance period.

Post hoc we questioned whether the magnitude of habitual caffeine intake might have affected the effectiveness of the green tea administration. Therefore we discriminated within the green tea group between low $(<300 \mathrm{mg} / \mathrm{d})$ and high $(>300 \mathrm{mg} / \mathrm{d})$ caffeine consumers. A level of $300 \mathrm{mg} / \mathrm{d}$, corresponding to three to four cups of coffee/d, was chosen as it corresponds approximately to the mean value of caffeine consumption in the Dutch population. We observed higher satiety in the fasted state $(P<0.05)$ and lower plasma leptin concentration $(P<0.001)$ in the high caffeine consumers compared with the low caffeine consumers at baseline (Table 5), but not after weight loss or weight regain. Body-weight regain was higher in the high caffeine consumers compared with the low caffeine consumers $(P<0.05$; Table 5$)$. Body-weight regain in the low caffeine consumers was not significantly different from placebo. Habitual caffeine consumption was not related to body composition or REE.

\section{Discussion}

The present experiment showed that green tea did not improve body-weight maintenance after a $7.5 \%$ bodyweight loss compared with placebo in originally overweight and moderately obese men and women. Moreover, no differences in metabolic and blood parameters were found between the green tea and the placebo group.

The lack of finding a positive effect of green tea on weight maintenance contradicts our hypothesis based upon the results of Dulloo et al. (1999). Dulloo et al. (1999) showed that green tea (containing $150 \mathrm{mg}$ caffeine/d and $375 \mathrm{mg}$ catechins/d, of which $270 \mathrm{mg}$ was epigallocatechin gallate) stimulated $24 \mathrm{~h}$ energy expenditure and fat oxidation. This effect was attributed to the content of caffeine and tea catechins. Caffeine acts through the inhibition of phosphodiesterase, an enzyme that degrades intracellular cyclic AMP, and through antagonism of the negative modulatory effect of adenosine on increased noradrenaline release (Dulloo et al. 1992). Tea catechins have been shown to inhibit catechol $O$-methyltransferase (Borchardt \& Huber, 1975), the enzyme that degrades noradrenaline. Taken together, both caffeine and catechins would result in an increased and/or prolonged effect of noradrenaline on energy and lipid metabolism. In this respect,
Dulloo et al. (1999) showed that the effect of green tea on energy expenditure and fat oxidation was greater than can be attributed to its caffeine content, indicating that the action of the catechins was necessary to elicit a response from the relatively low dose of caffeine. However, Rumpler et al. (2001) showed that oolong tea, also rich in caffeine and catechins (containing $270 \mathrm{mg}$ caffeine/d and $668 \mathrm{mg}$ catechins/d, of which $244 \mathrm{mg}$ was epigallocatechin gallate), increased $24 \mathrm{~h}$ energy expenditure and fat oxidation, but its effect was solely due to its caffeine content. The discrepancy in the results of the studies of Dulloo et al. (1999) and Rumpler et al. (2001) and in the mechanisms behind the effect of green and oolong tea can be attributed to differences in protocol between the two studies. There were differences in the dose of caffeine $(150$ v. $270 \mathrm{mg} /$ d), the number of administrations (three $v$. five times), the period of administration (from breakfast until dinner $v$. from 08.30 to 14.30 hours) and the way of administration (capsules $v$. tea drink).

In the present study, we used a similar daily dose of green tea, the same number of administrations, the same time period, and the same way of administration as reported by Dulloo et al. (1999). However, we did not observe the expected effect of green tea on energy expenditure and fat oxidation. This can be explained by several factors.

Dulloo et al. (1999) investigated the effects of green tea on the short term $(24 \mathrm{~h})$ using a protocol in which the subjects had to withdraw from caffeine-containing foods and beverages from $24 \mathrm{~h}$ before and until the end of the experiment. Moreover, the subjects in that study were relatively low caffeine consumers $(100-200 \mathrm{mg} / \mathrm{d})$. On the contrary, the subjects in the present experiment were investigated in a free-living condition, in which they had no restrictions, for example, with respect to caffeine consumption. This means that besides the treatment, the subjects had their habitual caffeine intake, varying approximately from 0 to $1000 \mathrm{mg} / \mathrm{d}$. It is therefore probable that the magnitude of the habitual caffeine intake may have overruled the effectiveness of the green tea. In this regard, the low caffeine consumers showed a stronger weight maintenance compared with the high caffeine consumers. This could possibly indicate that supplementation with green tea may only be effective when habitual caffeine intake is low and that a much higher dose is required when habitual caffeine intake is high. With respect to this, it is possible that the greater weight regain observed in the high caffeine

Table 5. Habitual caffeine consumption, satiety and leptin at baseline, and percentage body-weight regain of the green tea group for high ( $n$ 32) and low ( $n$ 19) habitual caffeine consumers*

(Mean values and standard deviations)

\begin{tabular}{lllllll}
\hline & \multicolumn{2}{l}{ High caffeine consumers } & & \multicolumn{2}{c}{ Low caffeine consumers } \\
\cline { 2 - 3 } & Mean & SD & & Mean & SD & $P$ value \\
\hline Caffeine consumption $(\mathrm{mg} / \mathrm{d})$ & 511 & 167 & & 149 & 90 & $<0.0001$ \\
Baseline satiety $(\mathrm{mm}$ VAS) & 35 & 14 & & 28 & 8 & $<0.05$ \\
Baseline leptin $(\mu \mathrm{g} / \mathrm{ml})$ & $18 \cdot 8$ & $9 \cdot 8$ & & $27 \cdot 6$ & $15 \cdot 2$ & $<0.001$ \\
Percentage body-weight regain & 39 & 17 & 16 & 11 & $<0.05$ \\
\hline
\end{tabular}

VAS, visual analogue scale (fasting state before breakfast).

${ }^{*}$ For details of procedures, see p. 432. 
consumers can be attributed to some saturation of the ability of green tea to further stimulate noradrenalinerelated mechanisms, as both green tea and caffeine seem to produce at least part of their effect through mechanisms involving noradrenaline. Another possible explanation for failing to extrapolate the short-term findings of Dulloo et al. (1999) on the long term may be habituation to green tea (or caffeine) during prolonged administration. Furthermore, the placebo group showed increased cognitive restraint eating during the weight-maintenance period. This increase was not observed in the green tea group. This might explain why the placebo group showed similar effects on weight regain as the green tea group, although the green tea group was expected to result in stronger weight maintenance. In this respect, it has been previously shown that increased cognitive restraint is related to weight maintenance (Westerterp-Plantenga et al. 1998). However, we have no explanation about the increase in cognitive restraint in the placebo group, as both groups underwent the same protocol and received the same instructions.

A last possible explanation for failing to confirm the findings of Dulloo et al. (1999) is that in the present study the majority of the subjects consisted of women. It is possible that the impact of green tea on energy expenditure and fat oxidation is greater in men than in women. In the present study, we did not observe an effect of green tea when considering men alone. However, this might also be explained by a lack of power when considering men and women apart.

Body-weight regain during the weight-maintenance period was mainly due to FFM. During rapid bodyweight loss, substantial amounts of glycogen and water are lost together with fat, especially during the first phase of weight loss. It is therefore possible that during bodyweight regain glycogen and water are recovered first, while recovery of fat occurs at a later time.

Interestingly, high caffeine consumers had a lower plasma leptin concentration at baseline, indicating that the habitual use of caffeine may reduce leptin levels. This was independent of REE or FFM, since these were not related to caffeine consumption. Also, fasted satiety at baseline was higher in the high caffeine consumers. However, it is not clear whether these differences in circulating leptin and satiety at baseline may explain the difference in weight regain observed in the high and low caffeine consumers.

We conclude that green tea did not improve weight maintenance after a weight loss of $7.5 \%$ in originally overweight and moderately obese subjects. The stronger weight maintenance with green tea in the low caffeine consumers compared with the high caffeine consumers indicates that the magnitude of habitual caffeine intake may affect the effectiveness of green tea administration.

\section{References}

Borchardt RT \& Huber JA (1975) Catechol O-methyltransferase. 5. Structure-activity relationships for inhibition by flavonoids. $J$ Med Chem 18, 120-122.

Dulloo AG, Duret C, Rohrer D, Girardier L, Mensi N, Fathi M,
Chantre P \& Vandermander J (1999) Efficacy of green tea extract rich in catechin polyphenols and caffeine in increasing 24-h energy expenditure and fat oxidation. Am J Clin Nutr 70, 1040-1045.

Dulloo AG, Seydoux J \& Girardier L (1992) Potentiation of the thermogenic antiobesity effects of ephedrine by dietary methylxanthines: adenosine antagonism or phosphodiesterase inhibition? Metabolism 41, 1233-1241.

Goldstein DJ (1992) Beneficial effects of modest weight loss. Int J Obes Relat Metab Disord 16, 397-415.

Goris AHC, Meijer EP, Kester A \& Westerterp KR (2001) Use of triaxial accelerometer to validate reported food intakes. Am J Clin Nutr 73, 549-553.

Ekelund U, Yngve A, Sjostrom M \& Westerterp K (2000) Field evaluation of the Computer Science and Application's Inc. activity monitor during running and skating training in adolescent athletes. Int J Sports Med 21, 586-592.

Herman CP \& Polivy J (1980) Restrained eating. In Obesity, pp. 208-224 [AJ Stunkard, editor]. Philadelphia, PA: W.B. Saunders.

Kramer FM, Jeffery RW, Forster JL \& Snell MK (1989) Longterm follow-up of behavioral treatment for obesity: patterns of weight regain among men and women. Int $J$ Obes Relat Metab Disord 13, 123-136.

Pasman WJ, Saris WHM, Muls E, Vansant G \& Westerterp-Plantenga MS (1999) The effect of exercise training on long-term weight maintenance in weight-reduced men. Metabolism 48, $15-21$.

Pasman WJ, Westerterp-Plantenga MS, Muls E, Vansant G, van Ree J \& Saris WHM (1997a) The effectiveness of long-term fiber supplementation on weight maintenance in weight reduced women. Int J Obes Relat Metab Disord 21, 548-555.

Pasman WJ, Westerterp-Plantenga MS \& Saris WHM (1997b) The effectiveness of long-term supplementation of carbohydrate, chromium, fiber and caffeine on weight maintenance. Int J Obes Relat Metab Disord 21, 1143-1151.

Pi-Sunyer FX (1993) Medical hazards of obesity. Ann Intern Med 119, 655-660.

Rumpler W, Seale J, Clevidence B, Judd J, Wiley E, Yamamoto S, Komatsu T, Sawaki T, Ishikura Y \& Hosoda K (2001) Oolong tea increases metabolic rate and fat oxidation in men. J Nutr 131, 2848-2852.

Schoeller DA, van Santen E, Peterson DW, Diez W, Jaspan J \& Klein PD (1980) Total body water measurement in humans with ${ }^{18} \mathrm{O}$ and ${ }^{2} \mathrm{H}$ labeled water. Am J Clin Nutr 33, 2686-2693.

Schoffelen PFM, Westerterp KR, Saris WHM \& ten Hoor F (1997) A dual respiration chamber with automated calibration. J Appl Physiol 83, 2064-2072.

Seidell JC (1995) Obesity in Europe. Obes Res 3, Suppl. 2, 249s-259s.

Stunkard AJ \& Messick S (1985) The three factor eating questionnaire to measure dietary restraint, disinhibition and hunger. $J$ Psychosom Res 29, 71-83.

van Gaal LF, Wauters MA \& De Leeuw IH (1997) The beneficial effects of modest weight loss on cardiovascular risk factors. Int J Obes Relat Metab Disord 21, Suppl. 1, S5-S9.

van Marken Lichtenbelt WD, Westerterp KR \& Wouters L (1994) Deuterium dilution as a method for determining total body water: effect of test protocol and sampling time. Br J Nutr 72, 491-497.

Wadden TA, Stunkard AJ \& Liebschutz J (1988) Three-year follow-up of the treatment of obesity by very low calorie diet, behavior therapy, and their combination. J Consult Clin Psychol 56, 925-928.

Weir JBDV (1949) New methods for calculating metabolic rate with special references to protein metabolism. J Physiol 109, 1-9. 
Westerterp KR (2001) Pattern and intensity of physical activity. Nature 410, 539.

Westerterp-Plantenga MS (2001) Analysis of energy density of food in relation to energy intake regulation in human subjects. Br J Nutr 85, 351-361.

Westerterp-Plantenga MS, Kempen KPG \& Saris WHM (1998) Determinants of weight maintenance in women after diet-induced weight reduction. Int J Obes Relat Metab Disord 22, 1-6.

Westerterp-Plantenga MS, Rolland V, Wilson SAJ \& Westerterp KR (1999) Satiety related to $24 \mathrm{~h}$ diet-induced thermogenesis during high protein/carbohydrate vs. high fat diets measured in a respiration chamber. Eur J Clin Nutr 53, $495-502$. 